\title{
Effect of the angle of shoulder flexion on the reach trajectory of children with spastic cerebral palsy.
}

\section{$\operatorname{AUTHOR}(\mathrm{S})$ :}

Furuya, Makiko; Ohata, Koji; Izumi, Keisuke; Matsubayashi, Jun; Tominaga, Wataru; Mitani, Akira

\section{CITATION:}

Furuya, Makiko ... [et al]. Effect of the angle of shoulder flexion on the reach trajectory of children with spastic cerebral palsy.. Research in developmental disabilities 2014, 36: 413418

\section{ISSUE DATE:}

2014-11-11

URL:

http://hdl.handle.net/2433/192766

\section{RIGHT:}

(c) 2014 Elsevier Ltd.; この論文は出版社版でありません。引用の際には 出版社版をご確認ご利用ください。; This is not the published version. Please cite only the published version. 
Tile:

Effect of the angle of shoulder flexion on the reach trajectory of children with spastic cerebral

palsy

Key words: Cerebral palsy, Shoulder flexion angle, Reach, Trajectory

Authors and Affiliations:

Makiko Furuya a , Koji Ohata ${ }^{\text {b }}$, Keisuke Izumi ${ }^{b}$, Jun Matsubayashi ${ }^{\text {a }}$, Wataru Tominaga a, Akira

Mitani $^{\text {a }}$

${ }^{a}$ Laboratory of Neurorehabilitation, Department of Human Health Sciences, Graduate School of

Medicine, Kyoto University, Kyoto, Japan

b Department of Physical Therapy, Human Health Sciences, Graduate School of Medicine,

Kyoto University, Kyoto, Japan

Corresponding author:

Dr. Akira Mitani 
Laboratory of Neurorehabilitation, Department of Human Health Sciences, Graduate School of Medicine, Kyoto University

53 Kawaharacho, Syogoin, Sakyo-ku, Kyoto 606-8507, Japan

Phone \& Fax: +81 75751 3913, E-mail: mitani.akira.6z@kyoto-u.ac.jp

ABSTRACT: Many children with cerebral palsy (CP) use a wheelchair during activities of daily living and often extend their hand upward and downward to reach objects in a seated position in a wheelchair. However, the effect of shoulder position on reaching movements of children with CP is not established. The purpose of this study was to determine the effect of the angle of shoulder flexion on the reach trajectory of children with spastic CP. Seven children with mild CP [Manual Ability Classification System (MACS) levels I-II], five children with severe CP (MACS levels III-V) and six typically developing (TD) children participated. We prepared the device to have a top board with variable tilting angle in order to reduce the effect of gravity imposing on reaching movements. By using this device, the subjects could extend their arm by sliding it on the board to push a target button. The reaching movements were performed with the more affected hand at three angles $\left(60^{\circ}, 90^{\circ}\right.$ and $\left.120^{\circ}\right)$ of shoulder flexion and captured using a camera motion analysis system. Subjects in the TD and mild CP groups reached the 
target at $60^{\circ}, 90^{\circ}$ and $120^{\circ}$ of shoulder flexion. Subjects of the severe CP group reached the target at $60^{\circ}$ and $90^{\circ}$ of shoulder flexion, but two of the subjects could not reach the target at $120^{\circ}$ of shoulder flexion. The TD and mild CP groups showed smooth and almost straight trajectories at all three angles of shoulder flexion; however, the reach trajectory in the subjects with severe CP changed with the angle of shoulder flexion. A large angle of shoulder flexion induced great outward deviation in the trajectory. These findings suggest that the difficulty of the reaching task is changed depending on the shoulder joint angle in children with severe $\mathrm{CP}$ and that therapeutic interventions for children with severe CP should be provided in a manner appropriate for the shoulder joint angle. 


\section{Introduction}

Cerebral palsy (CP) is one of the most common neurologic problems in children referred to physical therapists. Children with $\mathrm{CP}$ have impairment of motor function that is due to a non-progressive interference, lesion, or abnormality in the immature brain. About one third of children with CP are non-walking (SoCPiE, 2002) and about $60 \%$ of them have problems with upper limb function (Arner et al., 2008). Upper limb function to reach, grasp, transport and release objects is needed for activities of daily living (ADL) such as eating, bathing and grooming. Children with disabilities of upper limb function have reduced their ADL.

Reaching is a necessary behavior for ADL. Many children with CP use a wheelchair during ADL and often extend their hand upward and downward to reach objects from a seated position. However, the effect of shoulder position on reaching movements of children with CP is not established. Some studies have examined shoulder kinematics of reaching movements in children with CP. Children with hemiplegic CP show a reduced range of motion in the shoulder (Coluccini et al., 2007) and reduced shoulder elevation during reaching (Jasper et al., 2011). These reports suggest that reaching movements of the children with CP are changed depending on the angle of shoulder flexion. Our clinical impression is that the reach trajectory of children with severe CP would show deviation depending on the angle of the shoulder flexion. 
The purpose of this study was to determine the effect of the angle of shoulder flexion on the reach trajectory of children with spastic CP.

\section{Methods}

\subsection{Subjects}

Following approval from the Ethics Committee of Kyoto University Hospital and Graduate School of Medicine (E1072), twelve children with spastic CP and six typically developing (TD) children participated in this study. Informed consent was obtained from children and parents prior to participation. The children with spastic CP had sensorimotor impairments in at least one arm, were able to hold a sitting position, and had cognitive skills sufficient to understand instructions. Children with severe cognitive deficits that precluded performance of the task, or severe range of motion impairment of the shoulder and elbow were excluded. Children with CP were classified into two groups using the Manual Ability Classification System (MACS) (Eliasson et al., 2006): a mild CP group (n=7) (MACS levels I-II) in which the children were able to handle objects by themselves, and a severe CP group (n=5) (MACS levels III-V) in which the children required some assistance to handle objects (Table 1). 


\subsection{Device and task}

In order to reduce the effect of gravity imposing on reaching movements, we prepared the device having a top board with variable tilting angle (Fig. 1A). The subject was seated in a semicircular cutout section of the board with the reaching arm relaxed on the board. The top board height was adjusted so that the top plate was at the subject's armpit height, and the angle of the top board was set at $60^{\circ}, 90^{\circ}$ and $120^{\circ}$ of the shoulder flexion (Fig. 1B). The subjects were able to extend their arm by sliding it on the board. The subject's trunk was fixed in the semicircular cutout section of the board to prevent rotation, and if necessary, we supported the trunk from the rear.

The target button (15 cm in diameter) was placed on the board directly in front of the midline of the subject at the arm's-length distance that was defined as the distance from the medial axillary border to the crease of the extended elbow. The subject's hand was placed at the start position that was near the subject and aligned with the sagittal midline of the trunk at the beginning of each trial. The subjects were instructed to reach and push the target button. Reaching movements were self-paced and made with the more affected arm (with the non-dominant arm in TD group), and three times of reaching to the target were performed at each angle of shoulder flexion. 


\subsection{Measurements and data analysis}

Reflective markers were attached bilaterally on the acromion process, lateral epicondyle of the humerus, and head of third metacarpal. A camera (B-CAM, DKH, Japan) was fixed about 3 meters above the subject perpendicular to the floor. A camera motion analysis system (Frame-DIAS IV, DKH, Japan) was used to capture reaching movements at $60 \mathrm{~Hz}$ and the kinematic data were recorded for off-line analyses.

Reach trajectory was recorded using the reflective marker placed on the head of third metacarpal. Deviation, which was defined as the perpendicular distance between the point in the trajectory and the straight line from the head of third metacarpal at the start position to the target (Fig. 2), was analyzed at the longest reaching in three trials in each angle of shoulder flexion. The mean of the deviations was calculated in the reaching trial.

\subsection{Statistical analysis}

The mean values of the deviation of each trajectory at three angles of shoulder flexion were compared with a repeated measures two-way ANOVA. Group (TD, mild CP, severe CP) was the between-subject factor, and shoulder flexion angle $\left(60^{\circ}, 90^{\circ}, 120^{\circ}\right)$ was the within-subject factor. 
Bonferroni's test was used for subsequent post-hoc multiple comparisons. The statistical analyses were run with SPSS statistics Ver.17 (Japan IBM, Inc., Japan). Significance was set at $\mathrm{p}<0.05$.

\section{Results}

\subsection{Observation of the trajectory}

Subjects of the TD $(n=6)$ and mild CP $(n=7)$ groups reached the target at $60^{\circ}, 90^{\circ}$ and $120^{\circ}$ of shoulder flexion. Subjects $(n=5)$ of the severe CP group reached the target at $60^{\circ}$ and $90^{\circ}$ of shoulder flexion, but two of the subjects could not reach the target at $120^{\circ}$ of shoulder flexion. The TD group showed smooth and almost straight trajectories at all three angles $\left(60^{\circ}, 90^{\circ}\right.$, $120^{\circ}$ ) of shoulder flexion (Fig. 3A). Most subjects in the mild CP group showed similar trajectory to the TD group. The trajectories were smooth and almost straight at all three angles $\left(60^{\circ}, 90^{\circ}, 120^{\circ}\right)$ of shoulder flexion. Two subjects of the mild CP group showed slight outward deviation in the reach trajectory at $120^{\circ}$ of shoulder flexion (Fig. 3B), however, there were no statistically significant differences between the TD and mild CP groups. Contrary to the TD and mild CP groups, deviation of trajectory was observed at $60^{\circ}, 90^{\circ}$ and $120^{\circ}$ of the shoulder 
flexion in the severe CP group. The trajectories curved outward and showed smaller shaking movements (Fig. 3C).

\subsection{Analysis}

The mean deviations of reach trajectories of the TD group were $1.0 \pm 0.5 \mathrm{~cm}( \pm \mathrm{SD}), 1.2 \pm$ $0.5 \mathrm{~cm}$ and $1.1 \pm 0.3 \mathrm{~cm}$ at $60^{\circ}, 90^{\circ}$ and $120^{\circ}$ of shoulder flexion, respectively (Fig. 4). The mean deviations of reach trajectories of the mild CP group were $1.5 \pm 0.9 \mathrm{~cm}, 1.4 \pm 0.7 \mathrm{~cm}$ and $2.1 \pm 1.5 \mathrm{~cm}$ at $60^{\circ}, 90^{\circ}$ and $120^{\circ}$ of shoulder flexion, respectively. The mean deviations of reach trajectories of the severe CP group were $4.7 \pm 2.2 \mathrm{~cm}, 5.9 \pm 3.2 \mathrm{~cm}$ and $10.9 \pm 7.0 \mathrm{~cm}$ at $60^{\circ}, 90^{\circ}$ and $120^{\circ}$ of shoulder flexion, respectively. These mean values of the deviations were compared with a two-way repeated measures ANOVA with factors 'group' and 'shoulder flexion angle'. Significant main effects were shown for 'group' $(F(2,15)=17.664, p<0.001)$ and 'shoulder flexion angle' $(\mathrm{F}(1.1,16.6)=6.129, \mathrm{p}=0.022)$. Furthermore, the interaction effect between 'group' and 'shoulder flexion angle' was significant $(F(2.2,16.6)=3.956, p=0.036)$, indicating that the difference on the effect of 'group' was affected by the effect of 'shoulder flexion angle’. Bonferroni's post-hoc test revealed statistically significant differences. At $60^{\circ}$ of shoulder flexion, the severe CP group showed greater deviation of reach trajectory compared 
with the TD $(p=0.001)$ and mild CP $(p=0.003)$ groups. At $90^{\circ}$ of shoulder flexion, the severe CP group showed greater deviation of reach trajectory compared with the TD $(\mathrm{p}=0.001)$ and mild CP $(\mathrm{p}=0.001)$ groups. At $120^{\circ}$ of shoulder flexion, the severe CP group showed greater deviation of reach trajectory compared with the TD $(p=0.002)$ and mild CP $(p=0.004)$ groups. These results indicated that the deviation of reach trajectory in the severe $\mathrm{CP}$ group was significantly greater than that in the TD and mild CP groups at $60^{\circ}$ to $120^{\circ}$ of shoulder flexion. Significant differences were also seen between $60^{\circ}$ of shoulder flexion and $120^{\circ}$ of shoulder flexion $(\mathrm{p}=0.011)$ and between $90^{\circ}$ of shoulder flexion and $120^{\circ}$ of shoulder flexion $(\mathrm{p}=$ 0.003) in the severe CP group. These results indicated that the angle of the shoulder flexion $\left(60^{\circ}\right.$ to $120^{\circ}$ ) had a significant effect on the reach trajectory in the severe CP group: a large angle of the shoulder flexion induced great outward deviation.

\section{Discussion}

It has been reported that children with bilateral CP exhibit less straight reaching movements than typically developing children (van der Heide et al., 2005). This supports our findings. In the present study, the subjects extended their arm by sliding it on the board to reduce the effect 
of gravity imposing on reaching movements. The TD and mild CP groups showed smooth and almost straight trajectories at all three angles of shoulder flexion; however, the reach trajectories of the children with severe $\mathrm{CP}$ showed outward deviation at $60^{\circ}$ to $120^{\circ}$ of shoulder flexion. The deviation at $120^{\circ}$ of shoulder flexion was significantly larger than that at $60^{\circ}$ and $90^{\circ}$ of shoulder flexion. Taking these findings together, the present study demonstrates that a reach trajectory at $60^{\circ}$ to $120^{\circ}$ of shoulder flexion in the children with severe CP (MACS levels III-V) changes with the angle of shoulder flexion: a large angle of shoulder flexion induces great outward deviation in the trajectory.

Similar outward deviations of reach trajectory are well documented in individuals with moderate to severe stroke. In moderately to severely impaired individuals with stroke, abnormal muscle coactivation occurs in the paretic upper limb, known as flexion synergy (Brunnstrom, 1970). The synergy involves the shoulder abduction with shoulder external rotation and extension and the elbow flexion (Sukal et al., 2007; Ellis et al., 2007; 2008; Miller \& Dewald, 2012) and leads outward deviation of the reach trajectory. The abnormal shoulder abduction with elbow flexion following stroke has been attributed to reorganization of cortical neuronal elements (Cao et al., 1994), changes in spinal interneuronal excitability (Dewald et al., 1999), increased dependence on residual brainstem descending pathways (Sukal et al., 2007), and 
increased overlap of cortical representation (Yao et al., 2009). The same neuronal mechanisms may produce the outward deviation of the reach trajectory in the children with severe CP.

Another possible factor in the outward deviation in reach trajectory is the effect of gravity. In the present study, in order to reduce the effect of gravity, the subjects put their reaching arm on the board and extended their arm by sliding it. It is thought that the effect of gravity imposing on reaching movements was considerably reduced compared to that on normal reaching movements, but was not completely removed. Particularly, at $120^{\circ}$ of shoulder flexion, the elbow was pulled downward by gravity and the reach trajectory might have been deviated outward. However, this study showed that the reach trajectory significantly deviated outward even at $60^{\circ}$ of shoulder flexion, in which reaching movements were downward and were assisted by gravity. This finding reinforces that reach trajectory deviates outward in children with severe CP. In the present study, we did not observe abnormal flexion of elbow, wrist and finger that were involved in the flexion synergy following stroke (Dewald et al., 1995; Dewald \& Beer 2001). This may be due to the device prepared for reducing gravity. The top board with tilting angle might reduce or prevent the flexion of elbow, wrist and finger of the upper limb sliding on the board.

In conclusion, the present study demonstrates that the reach trajectory of the children with 
severe CP (MACS levels III-V) changes with the angle $\left(60^{\circ}, 90^{\circ}\right.$ and $\left.120^{\circ}\right)$ of shoulder flexion under a reduced gravity condition: a large angle of shoulder flexion induces great outward deviation in the trajectory. This suggests that the difficulty of the reaching task will be changed depending on the shoulder joint angle in individuals with severe CP. Our results may provide a basic foundation to develop more effective rehabilitation interventions for the paretic upper limb of children with severe CP.

\section{Conflict of interest}

The authors declared no conflicts of interest with respect to the authorship and/or publication of this article.

\section{Acknowledgements}

This work was supported in part by JSPS KAKENHI Grant-in-Aid for JSPS Fellows Numbers 242272. 


\section{References}

Arner, M., Eliasson, A-C., Nicklasson, S., Sommerstein, K., \& Hägglund, G. (2008). Hand function in cerebral palsy. Report of 367 children in a population-based longitudinal health care program. The Journal of Hand Surgery, 33A, 1337-1347.

doi : 10.1016/j.jhsa.2008.02.032

Brunnstrom, S. (1970). Movement therapy in hemiplegia : a neurophysiological approach. New York: Harper \& Row, (Chapter 1).

LC control number: 70106334

Cao, Y., Vikingstad, E.M., Huttenlocher, P.R., Towle, V.L., \& Levin, D.N. (1994). Functional magnetic resonance studies of the reorganization of the human hand sensorimotor area after unilateral brain injury in the perinatal period. Proceedings of the National Academy of Sciences of the United States of America, 91, 9612-9616.

PMID[PubMed ID] : 7937815

Coluccini, M., Maini, E.S., Martelloni, C., Sgandurra, G., \& Cioni, G. (2007). Kinematic 
characterization of functional reach to grasp in normal and in motor disabled children. Gait

\& Posture, 25, 493-501.

doi : 10.1016/j.gaitpost.2006.12.015

Dewald, J.P., Pope, P.S., Given, J.D., Buchanan, T.S., \& Rymer, W.Z. (1995). Abnormal muscle coactivation patterns during isometric torque generation at the elbow and shoulder in hemiparetic subjects. Brain, 118, 495-510.

doi : 10.1093/brain/118.2.495

Dewald, J.P., Beer, R.F., Given, J.D., McGuire, J.R., \& Rymer, W.Z. (1999). Reorganization of flexion reflexes in the upper extremity of hemiparetic subjects. Muscle \& Nerve, 22, 1209 1221.

doi : 10.1002/(SICI)1097-4598(199909)22:9<1209::AID-MUS7>3.0.CO;2-B

Dewald, J.P., \& Beer, R.F. (2001). Abnormal joint torque patterns in the paretic upper limb of subjects with hemiparesis. Muscle \& Nerve, 24, 273-283.

doi : 10.1002/1097-4598(200102)24:2<273::AID-MUS130>3.0.CO;2-Z 
Eliasson, A-C., Krumlunde-Sundholm, L., Rösblad, B., Beckung, E., Arner, M., Öhrvall, A-M., et al. (2006). The Manual Ability Classification System (MACS) for children with cerebral palsy: scale development and evidence of validity and reliability. Developmental Medicine and Child Neurology, 48, 549-554.

doi : 10.1111/j.1469-8749.2006.tb01313.x

Ellis, M.D., Acosta, A.M., Yao, J., \& Dewald, J.P. (2007). Position-dependent torque coupling and associated muscle activation in the hemiparetic upper extremity. Experimental Brain Research, 176, 594-602.

doi : 10.1007/s00221-006-0637-x

Ellis, M.D., Sukal, T., DeMott, T., \& Dewald, J.P. (2008). Augmenting clinical evaluation of hemiparetic arm movement with a laboratory-based quantitative measurement of kinematics as a function of limb loading. Neurorehabilitation and Neural Repair, 22, 321329.

doi : $10.1177 / 1545968307313509$ 
Jaspers, E., Desloovere, K., Bruyninckx, H., Klingels, K., Molenaers, G., Aertbeliën, E., et al.

(2011). Three-dimensional upper limb movement characteristics in children with hemiplegic cerebral palsy and typically developing children. Research in developmental disabilities, 32, 2283-2294.

doi : 10.1016/j.ridd.2011.07.038

Miller, L.C., \& Dewald, J.P. (2012). Involuntary paretic wrist/finger flexion forces and EMG increase with shoulder abduction load in individuals with chronic stroke. Clinical Neurophysiology, 123, 1216-1225.

doi : 10.1016/j.clinph.2012.01.009

Sukal, T.M., Ellis, M.D., \& Dewald, J.P. (2007). Shoulder abduction-induced reductions in reaching work area following hemiparetic stroke: neuroscientific implications. Experimental Brain Research, 183, 215-223.

doi : 10.1007/s00221-007-1029-6

SoCPiE: Surveillance of Cerebral Palsy in Europe. (2002). Prevalence and characteristics of 
children with cerebral palsy in Europe. Developmental Medicine and Child Neurology, 44,

633-640.

doi : 10.1111/j.1469-8749.2002.tb00848.x

van der Heide, J.C., Fock, J.M., Otten, B., Stremmelaar, E., \& Hadders-Algra, M. (2005).

Kinematic characteristics of reaching movements in preterm children with cerebral palsy.

Pediatric Research, 57, 883-889.

doi : 10.1203/01.PDR.0000157771.20683.14

Yao, J., Chen, A., Carmona, C., \& Dewald, J.P. (2009). Cortical overlap of joint representations contributes to the loss of independent joint control following stroke. Neuroimage, 45, 490499.

doi : 10.1016/j.neuroimage.2008.12.002 
Figure Legends

Figure 1. The device prepared for reducing the effect of gravity imposing on reaching movements. The device (A) had a top board with a variable tilting angle. The subject was seated in a semicircular cutout section of the board and extended the arm by sliding it on the board at $60^{\circ}(\mathrm{B}-1), 90^{\circ}(\mathrm{B}-2)$ and $120^{\circ}(\mathrm{B}-3)$ of shoulder flexion.

Figure 2. Measurement of trajectory deviation. (A) Reach trajectory was recorded using a reflective marker placed on the head of third metacarpal. (B) Deviation was obtained by calculating the perpendicular distance between the trajectory and a straight line from the start to the target.

Figure 3. Representative reach trajectories in the TD (A), mild CP (B) and severe CP (C) groups. Reaching movements of the head of third metacarpal were made from the start point (0) to the target using the left hand in (A) and (C) and the right hand in (B). Lines with light, intermediate and dark colors indicate trajectories at $60^{\circ}, 90^{\circ}$ and $120^{\circ}$ of shoulder flexion, respectively. Arrows on the vertical lines indicate the distance to the target in each subject. Abscissas represent the deviation of trajectory. 
Figure 4. Mean deviations of reach trajectories in the TD (green), mild CP (blue) and severe CP

(red) groups. Thin bars indicate standard deviation. Asterisks indicate statistically significant differences $(\mathrm{p}<0.05)$. Ordinate represents the mean deviation of reach trajectory, and abscissa represents the angle of shoulder flexion. 

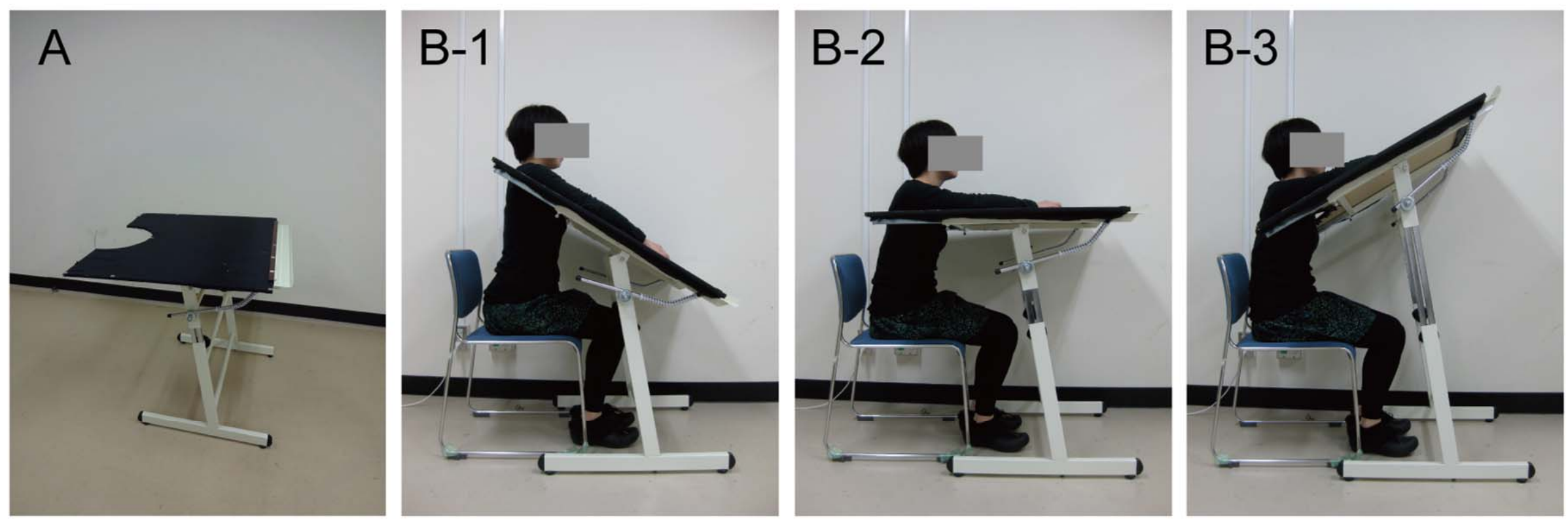

Figure 1 


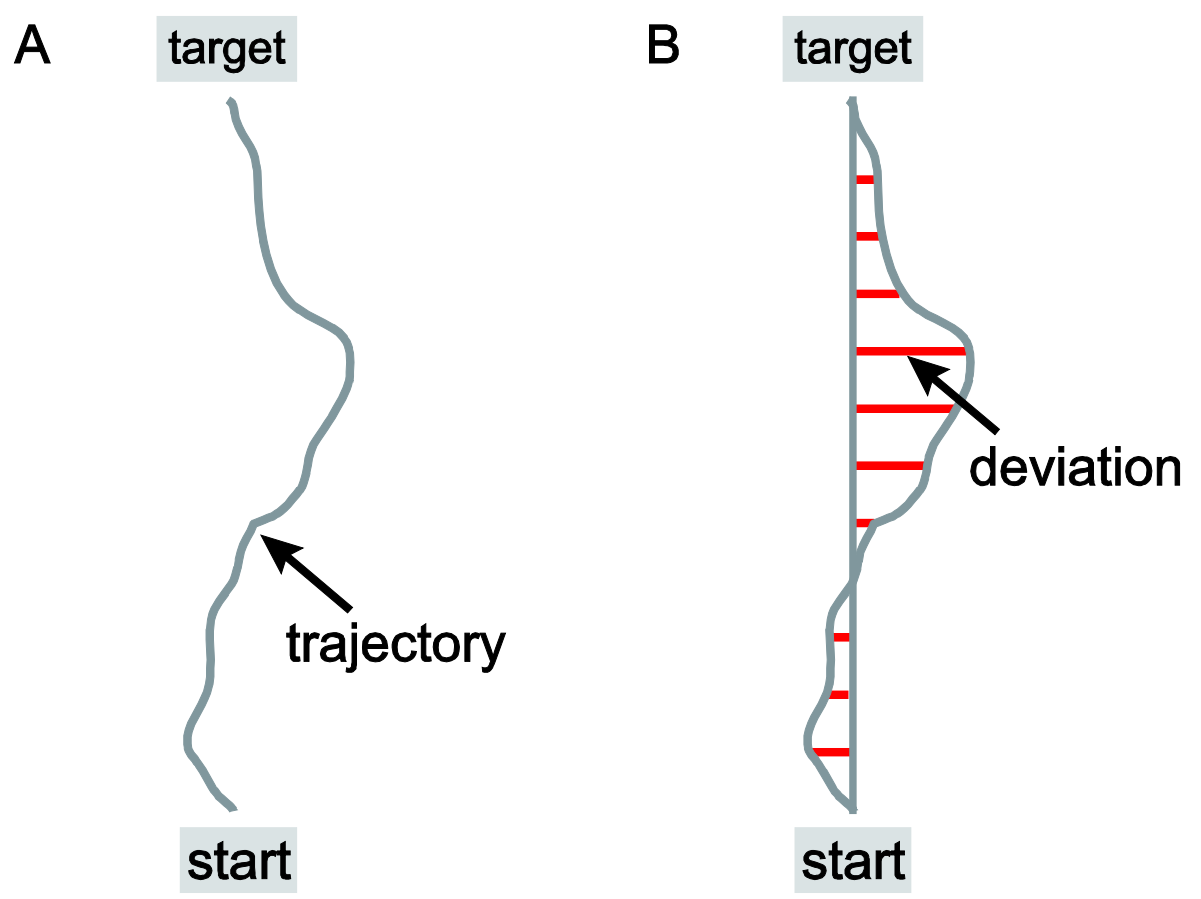

Figure 2 

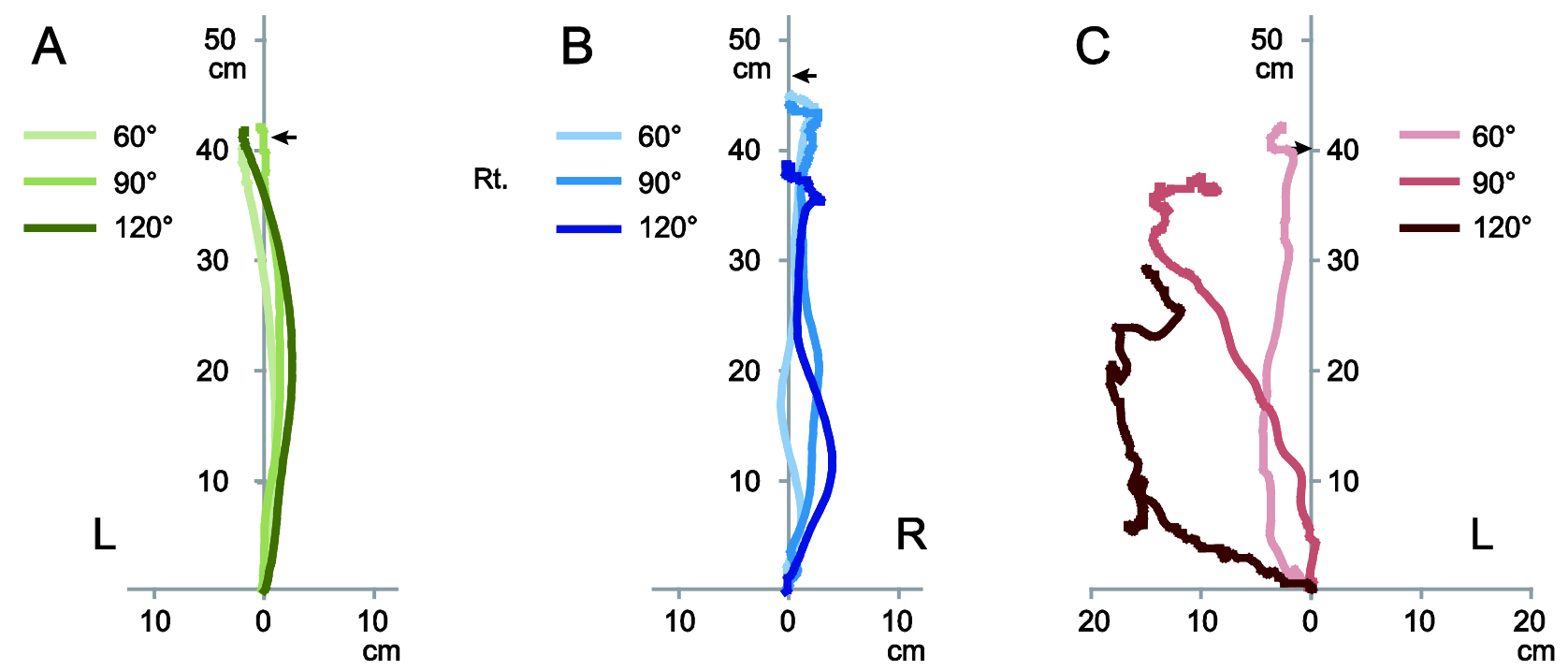

Figure 3 


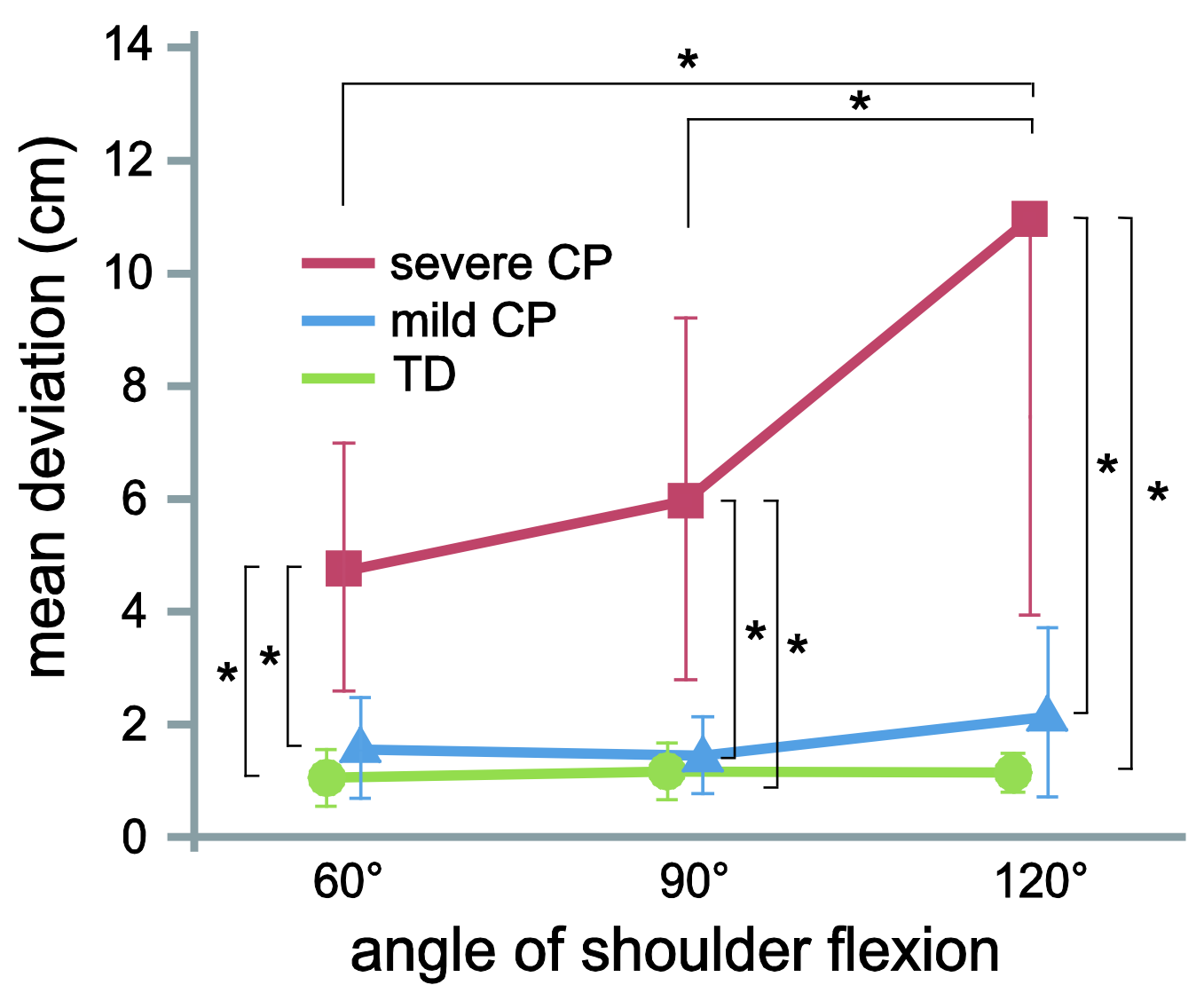

Figure 4 
Table 1. Characteristics of the subjects in the study.

\begin{tabular}{|c|c|c|c|c|c|c|c|}
\hline $\begin{array}{c}\text { Subject } \\
\text { ID }\end{array}$ & Gender & Age & $\begin{array}{l}\text { Height } \\
(\mathrm{cm})\end{array}$ & $\begin{array}{c}\text { Weight } \\
(\mathrm{kg})\end{array}$ & MACS & $\begin{array}{l}\text { Impairment } \\
\text { Distribution }\end{array}$ & $\begin{array}{c}\text { Preferred } \\
\text { Hand }\end{array}$ \\
\hline \multicolumn{8}{|c|}{ Severe CP group } \\
\hline s01 & $\mathrm{F}$ & 13 & 116.5 & 17.2 & III & Quadriplegia & right \\
\hline S02 & $M$ & 15 & 137.5 & 26.8 & V & Quadriplegia & right \\
\hline S04 & $\mathrm{F}$ & 17 & 138.3 & 48.4 & IV & Hemiplegia & left \\
\hline S05 & M & 17 & 157.4 & 42.0 & IV & Quadriplegia & right \\
\hline S09 & M & 10 & 123.0 & 24.1 & IV & Quadriplegia & left \\
\hline Mean & $2 \mathrm{~F} / 3 \mathrm{M}$ & $14.4 \pm 3.0$ & $134.5 \pm 15.8$ & $31.7 \pm 13.0$ & & & 2left/3right \\
\hline \multicolumn{8}{|c|}{ Mild CP group } \\
\hline S03 & $\mathrm{F}$ & 18 & 144.5 & 35.7 & II & Quadriplegia & left \\
\hline S06 & M & 16 & 142.0 & 38.2 & II & Quadriplegia & left \\
\hline S07 & $\mathrm{F}$ & 15 & 158.1 & 42.5 & II & Quadriplegia & right \\
\hline S08 & M & 18 & 172.5 & 57.9 & I & Diplegia & right \\
\hline S10 & $\mathrm{F}$ & 8 & 127.3 & 23.9 & II & Quadriplegia & right \\
\hline S11 & M & 15 & 153.7 & 33.8 & II & Diplegia & right \\
\hline S12 & M & 17 & 155.0 & 53.6 & I & Diplegia & right \\
\hline Mean & $3 F / 4 M$ & $15.3 \pm 3.5$ & $150.4 \pm 14.3$ & $40.8 \pm 11.7$ & & & 2left/5right \\
\hline \multicolumn{8}{|l|}{ TD group } \\
\hline Mean & $6 \mathrm{~F}$ & $9.2 \pm 1.9$ & $139.0 \pm 5.9$ & $31.5 \pm 5.3$ & & & 1left/5right \\
\hline
\end{tabular}

MACS, Manual Ability Classification System. 